\title{
Avaliação do procedimento simplificado da NBR 15575 para determinação do nível de desempenho térmico de habitações
}

\author{
Evaluation of NBR 15575 simplified procedure for \\ determining the thermal performance level of dwellings
}

\section{Karin Maria Soares Chvatal}

\section{Resumo}

$\Delta$

norma brasileira NBR 15575: Edificações habitacionais Desempenho (ABNT, 2013) representa um avanço no setor da construção civil. É importante que se mantenha uma discussão constante sobre ela, a fim de estimular seu aprimoramento. Recentemente, alguns autores têm apresentado críticas aos métodos propostos pela referida norma, como incoerências entre seus procedimentos simplificado e de simulação. Este trabalho investiga as razões dessas incongruências, com o foco em habitações de interesse social. O método consiste na aplicação dos dois procedimentos da Norma a uma habitação unifamiliar térrea em três zonas bioclimáticas brasileiras, com variadas transmitâncias térmicas e absortâncias das paredes exteriores e da cobertura. Também foram conduzidas séries de estudos para a habitação com paredes com alta capacidade térmica e simulações horárias anuais para a edificação em condições reais de uso. Os resultados demonstraram que o impacto conjugado da transmitância e da absortância não é representado de forma adequada nos limites estabelecidos pelo procedimento simplificado, e também que a capacidade térmica influencia esses limites. Quanto à simulação anual, verificou-se que esta é a forma mais adequada de se avaliarem as distintas necessidades de desempenho quanto ao inverno e ao verão.

Palavras-chaves: NBR 15575. Desempenho térmico. Procedimento simplificado. Habitações de Interesse Social.
Abstract
The Brazilian NBR 15575 Standard: House-building performance (ABNT, 2013) represents a significant step forward for the Brazilian construction industry. It is important to keep an on-going discussion about its methods in order to encourage its improvement. Some authors have criticised the methods established by that standard, pointing to inconsistencies between the simplified procedure and the simulation procedure. This study investigates the reasons for these inconsistencies, focusing on social housing. The research method consisted of the application of both procedures on a single-storey house located in three Brazilian climate zones, with distinct envelope $U$-values and absorptancy. Simulations for the house whose walls have high thermal capacitance were also performed, as well as annual
simulations for the building in normal use conditions. The results showed that the joint impact of the $U$-value and absorptance is not adequately represented in the simplified method. It was also observed that thermal capacitance influences these limits. The annual simulation proved to be the best way to evaluate different performance requirements in the summer and winter.
Keywords: NBR 15575. Thermal performance. Simplified procedure. Social housing.

Karin Maria Soares Chvatal Universidade de São Paulo São Carlos - SP - Brasil

Recebido em 15/03/14 Aceito em 25/09/14 


\section{Introdução}

A norma brasileira NBR 15575: Edificações habitacionais - Desempenho (ABNT, 2013) tem causado grande impacto no setor da construção civil desde a publicação de sua primeira versão, em 2008. Como o setor não se considerava preparado para absorver as mudanças que ela impunha, solicitou sua revisão. Após um longo período de discussões, o texto original sofreu modificações, até resultar na versão atual, publicada em 19 de fevereiro de 2013 e válida a partir de 19 de julho de 2013.

Essa norma trata do desempenho das habitações, qualquer que seja seu número de pavimentos (em versão anterior, ela era limitada a edifícios habitacionais com até cinco pavimentos). Ela não é uma norma prescritiva, ou seja, não indica como o prédio deve ser construído, mas sim ao que ele deve atender para que tenha o desempenho desejado (mínimo, intermediário ou superior), independentemente de seu sistema construtivo. $\mathrm{O}$ objetivo final é atender às necessidades do usuário, as quais, por sua vez, se traduzem nos seguintes aspectos:

(a) segurança (segurança estrutural, contra fogo, no uso e na operação);

(b) habitabilidade (estanqueidade, desempenho térmico, acústico e lumínico, saúde, higiene e qualidade do ar, funcionalidade, acessibilidade, conforto tátil e antropodinâmico); e

(c) sustentabilidade (durabilidade, manutenibilidade e impacto ambiental).

Ela é composta de seis partes. Na primeira, requisitos gerais, são estabelecidas as exigências de desempenho com relação aos aspectos acima citados, considerando-se o prédio como um todo. Nas partes seguintes, são apresentadas as exigências específicas para os sistemas que compõem a edificação:

(a) sistemas estruturais (parte 2);

(b) sistemas de pisos (parte 3);

(c) sistemas de vedações verticais internas e externas (parte 4);

(d) sistemas de coberturas (parte 5); e

(e) sistemas hidrossanitários (parte 6).

O método de avaliação do desempenho térmico, objeto de estudo deste trabalho, é apresentado nas partes 1,4 e 5 .

Essa não é a única norma que trata do desempenho térmico de habitações no Brasil. $O$ primeiro documento normativo surgiu em 2005, a NBR 15220 - Desempenho térmico de edificações
(ABNT, 2005), o qual se restringe a habitações unifamiliares de interesse social (Parte 3 Zoneamento bioclimático brasileiro e diretrizes construtivas para habitações unifamiliares de interesse social). Nele se apresentam o zoneamento bioclimático brasileiro e recomendações de projeto para cada uma dessas zonas. Mais recentemente, surgiu o RTQ-R - Regulamento técnico da qualidade para o nível de eficiência energética em edificações residenciais, publicado em 2010 e atualizado em 2012, voltado a edificações uni e multifamiliares (INSTITUTO..., 2012). No RTQ-R são apresentados requisitos técnicos e métodos para a obtenção do nível de eficiência energética do edifício, que pode variar de A (mais eficiente) a $\mathrm{E}$ (menos eficiente). Essa informação permite a obtenção da Etiqueta Nacional de Conservação de Energia (Ence) para a habitação. No momento, possuir essa etiqueta é opcional, mas se tornará obrigatório nos próximos anos.

As normas e o regulamento acima citados podem ser considerados recentes, se comparados com os de muitos países, que foram implementados há muito mais tempo e com um histórico de revisões periódicas. Os documentos nacionais representam, portanto, um avanço no setor da construção civil brasileira, sendo importante que se mantenha uma discussão constante sobre sua aplicação e a viabilidade de seus métodos de cálculo, a fim de garantir seu aprimoramento. No entanto, há ainda poucos estudos no Brasil que analisam a ABNT NBR 15575.

Loura, Assis e Bastos (2011) aplicaram essa norma e o RTQ-R a um edifício multifamiliar, localizado na cidade do Rio de Janeiro. Obtiveram a classificação B para a eficiência energética dele, numa escala que variava de A (mais eficiente) a $\mathrm{E}$, enquanto o desempenho mínimo pela NBR 15575 não foi atendido. Os autores concluíram que esses resultados incoerentes devem ser mais bem investigados, pois contradições como essa podem dificultar a aplicação dessas exigências pelo setor da construção. Brito et al. (2012) analisaram os limites prescritos pelo procedimento simplificado da NBR 15575 para a zona 8 e observaram discrepâncias entre esse procedimento e o método de simulação. Marques e Chvatal (2013) também encontraram incoerências entre ambos os métodos ao avaliarem uma habitação de interesse social na cidade de São Carlos. Já Sorgato et al. (2012) apontam uma série de aspectos da NBR 15575 com falhas e apresentam sugestões para saná-las. Finalmente, Sorgato, Melo e Lamberts (2013) analisaram o método de simulação e identificaram grande variabilidade nos resultados, dependendo 
dos valores adotados como dados de entrada para o dia típico.

O presente artigo visa contribuir com o aperfeiçoamento da NBR 15575, ao analisar seu procedimento simplificado e compará-lo com os resultados obtidos pelo método de simulação. É indiscutível a relevância de métodos simplificados, porque permitem que edificações mais padronizadas e com baixo nível de complexidade sejam analisadas de forma expedita, sem a necessidade de simulação computacional. Para tal, o método simplificado deve ser capaz de avaliar de forma fidedigna o comportamento térmico do edifício, de modo que o nível de desempenho obtido por ele não seja superior ao verificado por meio de simulação. Caso contrário, pode ser aprovado um projeto que não apresente o desempenho mínimo necessário. Como estudos já citados (BRITO et al., 2012; MARQUES; CHVATAL, 2013) indicaram incoerência entre esses dois métodos propostos pela NBR 15575, nesta pesquisa procura-se investigar as razões dessas incongruências. $\mathrm{O}$ foco são habitações de interesse social, devido a sua simplicidade e por ser um tipo de projeto para o qual um método simplificado deveria ser capaz de representar de forma adequada o desempenho térmico.

\section{Método de avaliação do desempenho térmico de habitações segundo a NBR 15575}

O método de avaliação prescrito pela NBR 15575 (ABNT, 2013) considera duas alternativas para a obtenção do nível de desempenho: o procedimento simplificado; e o método de simulação computacional. Caso o desempenho mínimo não seja obtido através do procedimento simplificado, deve-se obrigatoriamente proceder ao método de simulação.

No procedimento simplificado, devem ser cumpridas três exigências:

(a) a área de abertura efetiva das janelas dos dormitórios e salas deve atender a um valor mínimo, que é indicado em porcentagem, em função da área de piso - essa exigência somente é válida caso não haja legislação específica para o local da obra (código de obras, sanitários, ou outros);

(b) as paredes exteriores devem atender aos valores prescritos na Tabela 1, para sua transmitância térmica (U) e a absortância $(\alpha)$ de sua superfície exterior - sua capacidade térmica $\left(\mathrm{C}_{\mathrm{t}}\right)$ também deve ser igual ou superior a 130 $\mathrm{kJ} / \mathrm{m}^{2} . \mathrm{K}$ (exceto para a zona bioclimática 8 ); e

(c) a cobertura deve atender aos valores prescritos na Tabela 1, para sua transmitância térmica (U) e a absortância $(\alpha)$ de sua superfície exterior - para a cobertura, são indicados distintos níveis de desempenho.

Tabela 1 - Valores-limite para as propriedades termofísicas das paredes exteriores e da cobertura, segundo o procedimento simplificado da ABNT NBR 15575

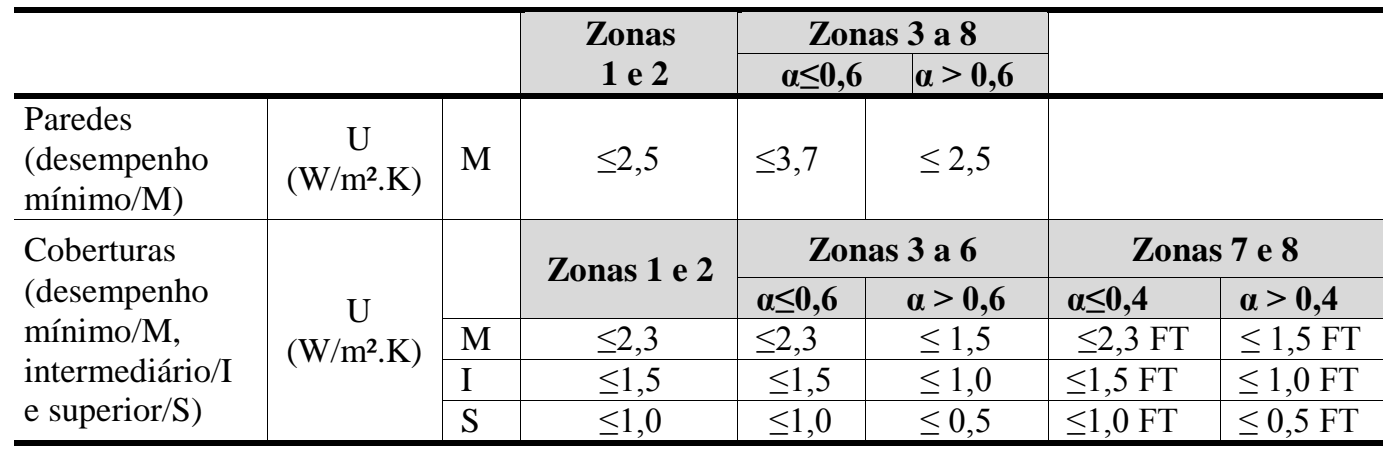

Fonte: adaptada da ABNT NBR 15575 (2013).

Nota: o fator de transmitância, FT, é definido na NBR 15220-3. Ele é adimensional e permite um valor-limite mais alto de $\mathrm{U}$, caso o ático seja ventilado (somente para as zonas 7 e 8). Para coberturas não ventiladas, $\mathrm{FT}=1$. 
Caso ao menos uma das exigências acima não seja cumprida, procede-se à simulação computacional. Esta deve ser executada por um programa de simulação dinâmica, validado pela ASHRAE 140 (AMERICAN..., 2011). Cada ambiente deve ser considerado como uma zona térmica (inclusive o ático), e analisados os desempenhos dos ambientes de maior permanência (salas e quartos). A modelagem não considera ganhos internos, e a taxa de ventilação deve ser constante e igual a 1 renovação de ar por hora. A simulação é feita para dias típicos de verão e de inverno ${ }^{1}$, cujos dados, para algumas capitais brasileiras, são fornecidos, embora incompletos.

A orientação solar deve estar de acordo com o projeto. Caso este não possua orientação definida, deve-se adotar, para o dia típico de verão, a janela do quarto ou da sala voltada ao oeste, e a outra face, se possível, ao norte. Para o dia típico de inverno, a janela do quarto ou da sala deve estar voltada para o sul, e a outra face, se possível, ao leste. A absortância da cobertura deve ser de acordo com o material adotado. Já para as paredes, caso a cor exterior não esteja definida, devem-se usar valores para as absortâncias de 0,3,0,5 e 0,7

Os critérios para a classificação dos níveis de desempenho se dão em função da diferença entre a temperatura mínima do ar no interior do ambiente em questão e a temperatura mínima do ar no exterior, para o inverno, ou tomando-se como referência a temperatura máxima, para o verão (Tabelas 2 e 3 ).

Caso o edifício não atinja o desempenho mínimo para o verão, é possível refazer as simulações, considerando uma das opções abaixo:

(a) adoção de proteção solar interna ou externa que reduza ao menos $50 \%$ da radiação solar direta;

(b) adoção de uma taxa de ventilação igual a 5 renovações de ar por hora; ou

(c) combinação das duas opções acima.

\section{Método da pesquisa}

\section{Etapas da pesquisa}

A metodologia foi desenvolvida em três etapas, descritas abaixo. Quadro 1 sintetiza o que foi feito em cada etapa.

Etapa 1: aplicação do procedimento simplificado e do método de simulação computacional prescritos pela NBR 15575 (ABNT, 2013) em uma habitação de interesse social com variadas combinações de transmitância térmica (U) e absortância $(\alpha)$ das paredes exteriores e da cobertura, em três zonas bioclimáticas brasileiras. O programa adotado para as simulações foi o EnergyPlus, versão 7.1 (DEPARTMENT..., 2012).

\section{Tabela 2 - Critérios de avaliação de desempenho térmico para condições de verão}

\begin{tabular}{ccc}
\hline \multirow{2}{*}{ Nível de desempenho } & \multicolumn{3}{c}{ Critérios } \\
\cline { 2 - 3 } & $\mathrm{Z}_{\mathrm{i}, \max }>\mathrm{T}_{\mathrm{e}, \max }$ & Zona 8 \\
\hline Insuficiente & $\mathrm{T}_{\mathrm{i}, \max } \leq \mathrm{T}_{\mathrm{e}, \max }$ & $\mathrm{T}_{\mathrm{i}, \max }>\mathrm{T}_{\mathrm{e}, \max }$ \\
Mínimo & $\mathrm{T}_{\mathrm{i}, \max } \leq \mathrm{T}_{\mathrm{e}, \max }$ \\
Intermediário & $\mathrm{T}_{\mathrm{i}, \max } \leq\left(\mathrm{T}_{\mathrm{e}, \max }-2{ }^{\circ} \mathrm{C}\right)$ & $\mathrm{T}_{\mathrm{i}, \max } \leq\left(\mathrm{T}_{\mathrm{e}, \max }-1{ }^{\circ} \mathrm{C}\right)$ \\
Superior & $\mathrm{T}_{\mathrm{i}, \max } \leq\left(\mathrm{T}_{\mathrm{e}, \max }-4{ }^{\circ} \mathrm{C}\right)$ & $\mathrm{T}_{\mathrm{i}, \max } \leq\left(\mathrm{T}_{\mathrm{e}, \max }-2{ }^{\circ} \mathrm{C}\right)$ \\
\hline
\end{tabular}

Fonte: adaptada da NBR 15575 (ABNT, 2013).

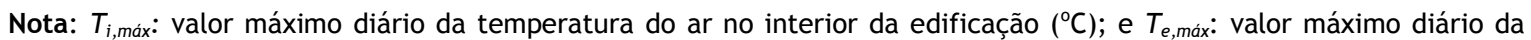
temperatura do ar exterior à edificação $\left({ }^{\circ} \mathrm{C}\right)$.

Tabela 3 - Critérios de avaliação de desempenho térmico para condições de inverno

\begin{tabular}{|c|c|c|}
\hline \multirow{2}{*}{ Nível de desempenho } & \multicolumn{2}{|c|}{ Critérios } \\
\hline & Zonas 1 a 5 & Zonas 6, 7 e 8 \\
\hline Insuficiente & $\mathrm{T}_{\mathrm{i}, \min }<\left(\mathrm{T}_{\mathrm{e}, \min }+3{ }^{\circ} \mathrm{C}\right)$ & \\
\hline Mínimo & $\mathrm{T}_{\mathrm{i}, \min } \geq\left(\mathrm{T}_{\mathrm{e}, \min }+3{ }^{\circ} \mathrm{C}\right)$ & Nestas zonas, este critério não \\
\hline Intermediário & $\mathrm{T}_{\mathrm{i}, \min } \geq\left(\mathrm{T}_{\mathrm{e}, \min }+5^{\circ} \mathrm{C}\right)$ & precisa ser verificado. \\
\hline Superior & $\mathrm{T}_{\mathrm{i}, \min } \geq\left(\mathrm{T}_{\mathrm{e}, \min }+7^{\circ} \mathrm{C}\right)$ & \\
\hline
\end{tabular}

Fonte: adaptada da NBR 15575 (ABNT, 2013).

Nota: $T_{i, m i n}$ : valor mínimo diário da temperatura do ar no interior da edificação $\left({ }^{\circ} \mathrm{C}\right)$; e $T_{e, \text { minn }}$ : valor mínimo diário da temperatura do ar exterior à edificação $\left({ }^{\circ} \mathrm{C}\right)$.

\footnotetext{
${ }^{1}$ Sorgato et al. (2012) questionam o termo "dia típico". No entanto, neste documento, adota-se esse termo para se referir ao dia representativo das condições de verão e de inverno do clima analisado.
} 


\section{Quadro 1 - Síntese das análises conduzidas em cada etapa}

\begin{tabular}{|c|c|c|}
\hline Etapa & O que foi feito? & Para quais situações? \\
\hline 1 & $\begin{array}{l}\text { Obtenção do nível de } \\
\text { desempenho das paredes } \\
\text { exteriores e da cobertura pelo } \\
\text { procedimento simplificado da } \\
\text { NBR } 15575 \text { (ABNT, 2013) } \\
\text { Obtenção do nível de } \\
\text { desempenho da habitação para o } \\
\text { verão e para o inverno, pelo } \\
\text { método de simulação da NBR } \\
\text { 15575 (ABNT, 2013) }\end{array}$ & $\begin{array}{l}\text { Habitação de interesse social (item Modelo de habitação e sua } \\
\text { localização) } \\
3 \text { climas (item Modelo de habitação e sua localização) } \\
4 \text { valores de transmitância térmica das paredes exteriores (item } \\
\text { Características construtivas) } \\
4 \text { valores de transmitância térmica da cobertura (item Características } \\
\text { construtivas) } \\
3 \text { valores de absortância das paredes exteriores (Características } \\
\text { construtivas) } \\
3 \text { valores de absortância da cobertura (item Características } \\
\text { construtivas) } \\
\text { Total de simulações: } 432 \text { para o verão e } 288 \text { para o inverno }\end{array}$ \\
\hline 2 & Idem à etapa 1 & $\begin{array}{l}\text { Habitação de interesse social (item Modelo de habitação e sua } \\
\text { localização) } \\
3 \text { climas (item Modelo de habitação e sua localização) } \\
3 \text { valores de transmitância térmica das paredes exteriores (item } \\
\text { Características construtivas) } \\
4 \text { valores de transmitância térmica da cobertura (item Características } \\
\text { construtivas) } \\
3 \text { valores de absortância das paredes exteriores (item Características } \\
\text { construtivas) } \\
3 \text { valores de absortância da cobertura (item Características } \\
\text { construtivas) } \\
\text { Total de simulações: } 324 \text { para o verão e } 216 \text { para o inverno } \\
\end{array}$ \\
\hline 3 & $\begin{array}{l}\text { Obtenção dos graus-hora de } \\
\text { desconforto por calor e por frio } \\
\text { anuais (item Forma de análise } \\
\text { dos resultados) }\end{array}$ & $\begin{array}{l}\text { Idem à etapa } 1 \\
\text { Total de simulações anuais: } 432\end{array}$ \\
\hline
\end{tabular}

Etapa 2: idem à etapa 1, considerando paredes exteriores com alta capacidade térmica.

Etapa 3: simulação horária da habitação para um ano climático, com as mesmas combinações da etapa 1, considerando ganhos internos e taxa de ventilação fixa de 5 renovações de ar por hora.

\section{Modelo de habitação e sua localização}

O modelo de habitação de interesse social adotado é uma casa térrea, unifamiliar, com dois dormitórios, área útil de $37,1 \mathrm{~m}^{2}$ e com todas as fachadas expostas ao exterior, ou seja, sem geminação (Figura 1). Os climas escolhidos consideraram a zona bioclimática mais fria (Curitiba, zona 1), uma entre as mais quentes (Manaus, zona 8) e uma intermediária (São Paulo, zona 3), de acordo com a NBR 15220 (ABNT, 2005). A habitação corresponde ao modelo mais utilizado no estado de São Paulo pela Caixa Econômica Federal. Esse modelo também foi considerado representativo do que é usualmente adotado nos estados do Paraná e do Amazonas. Foi feito um levantamento das habitações de interesse social unifamiliares térreas mais usuais na Companhia de Habitação do Paraná e na Superintendência de Habitação do Amazonas. Essas habitações foram caracterizadas de acordo com sua área útil, quantidade de cômodos e sua distribuição, materiais das paredes internas e piso, área de janela e de abertura efetiva. Concluiu-se que este modelo poderia representar também as habitações dos estados do Paraná e Amazonas, por possuir características muito similares.

Como a NBR 15575 (ABNT, 2013) estabelece que as simulações de verão e inverno sejam feitas para os ambientes de maior permanência em orientações específicas, foram adotadas as seguintes orientações:

(a) N1, para a análise de verão: janela da sala ao oeste e a outra parede externa ao norte; e

(b) N2, para a análise de inverno: janela do quarto 2 ao sul e a outra parede externa ao leste.

Para as simulações anuais, a habitação foi considerada na orientação N1. Quanto aos arquivos climáticos, foram adotados os disponibilizados por Roriz (2014). Parte dos dados dos dias típicos de verão e de inverno foram obtidos na própria NBR 15575 (ABNT, 2013): temperatura máxima diária, temperatura de bulbo úmido e amplitude diária de temperatura. No entanto, como o programa de simulação pede mais dados, além dos fornecidos pela Norma, os 
seguintes parâmetros foram estimados a partir do arquivo anual:

(a) direção e velocidade do vento: estimados a partir dos arquivos climáticos anuais (disponibilizados por Roriz (2014)); obtenção da rosa dos ventos do local, através do programa Climate Consultant (LIGGETT; MILNE, 2014); para Curitiba e São Paulo, adoção da direção predominante do vento e velocidade média correspondente aos meses mais quentes, para o dia típico de verão, e aos mais frios, para o dia típico de inverno; para Manaus, adoção da direção predominante e velocidade média correspondente no mês mais quente (setembro);

(b) data: solstícios de verão e inverno para Curitiba e São Paulo, e equinócio de setembro para Manaus, por este ser o mês mais quente;

(c) modelo para o cálculo da radiação solar nos dias típicos: foi adotado o modelo default do EnergyPlus, o ASHRAEClearSky; e

(d) nebulosidade: foi usado o valor de 0,5 para todas as simulações, considerando a faixa de zero a 1 , sendo 1 céu claro, e zero céu totalmente encoberto.

\section{Características construtivas}

Diversos valores foram atribuídos à transmitância térmica e à absortância das paredes exteriores e da cobertura, conforme indicado na Tabela 4. A capacidade térmica desses elementos foi mantida constante, assumindo-se um valor maior que o mínimo exigido pela Norma, de $130 \mathrm{~kJ} / \mathrm{m}^{2}$.K. A transmitância térmica variou de modo a se considerar uma faixa de valores mais abrangente que a indicada pela NBR 15575 (ABNT, 2013), no procedimento simplificado (Tabela 1). Também para a absortância, procurou-se adotar uma ampla faixa de valores, que incluísse desde cores claras até as mais escuras, considerando as medições de absortância de tintas feitas por Dornelles (2008).

Além disso, na etapa 2 da pesquisa foi feita uma série de estudos com paredes exteriores com alta capacidade térmica (Tabela 6).

Com exceção dos materiais das paredes exteriores e da cobertura, todas as outras características construtivas da habitação foram mantidas fixas. $\mathrm{O}$ Quadro 2 resume esses dados. As áreas efetivas de abertura das janelas da sala e dos dormitórios atendem às exigências do procedimento simplificado.

\section{Características da modelagem}

A habitação foi simulada considerando-se cada ambiente como uma zona térmica, inclusive o ático. No método de simulação pelos dias típicos, adotou-se 1 renovação de ar por hora em todos os ambientes e ausência de ganhos internos. Caso o desempenho mínimo não fosse atingido, alterou-se o número de renovações de ar para 5 renovações por hora, em todos os ambientes. Nas simulações horárias anuais, considerou-se o padrão de ganhos internos residencial sugerido pelo RTQ-R (INSTITUTO..., 2012) e 5 renovações de ar por hora. A temperatura do solo em todas as etapas foi estimada através do programa auxiliar do EnergyPlus, o Slab.

Figura 1 - Modelo de habitação de interesse social e orientações em relação ao norte

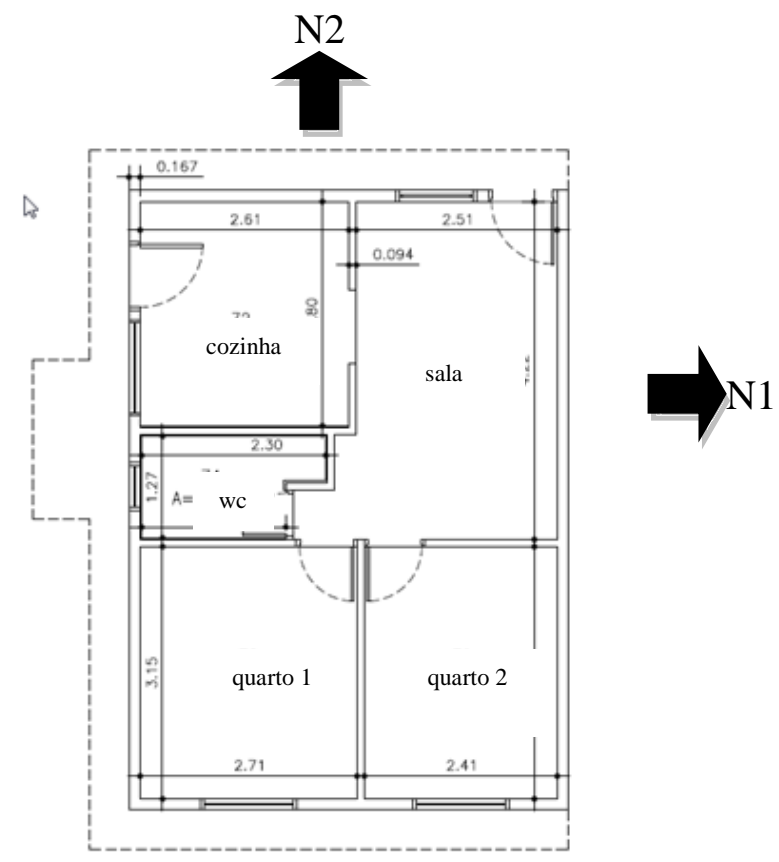

124 Chvatal, K. M. S 
Tabela 4 - Características das paredes exteriores e das cobertras simuladas

\begin{tabular}{|c|c|c|}
\hline \multicolumn{3}{|l|}{ Paredes exteriores } \\
\hline \multicolumn{3}{|l|}{$\alpha=0,9 / 0,6$ e 0,3} \\
\hline & $\begin{array}{c}\mathrm{U} \\
\left(\mathrm{W} / \mathrm{m}^{2} . \mathrm{K}\right)\end{array}$ & $\begin{array}{c}\mathrm{Ct} \\
\left(\mathrm{kJ} / \mathrm{m}^{2} . \mathrm{K}\right)\end{array}$ \\
\hline $\begin{array}{l}\text { painel de concreto moldado in loco, densidade de massa aparente igual a } \\
2.014 \mathrm{~kg} / \mathrm{m}^{3}(8 \mathrm{~cm})\end{array}$ & 4,39 & 161 \\
\hline bloco de concreto furado $(9 \mathrm{~cm})+\operatorname{argamassa}$ interior $(2,5 \mathrm{~cm})$ & 3,05 & 156 \\
\hline $\begin{array}{l}\text { argamassa exterior }(2,5 \mathrm{~cm})+\text { isolamento de poliestireno expandido }(0,5 \mathrm{~cm}) \\
+ \text { bloco de concreto furado }(9 \mathrm{~cm})+ \\
\text { argamassa interior }(2,5 \mathrm{~cm})\end{array}$ & 2,11 & 156 \\
\hline $\begin{array}{l}\text { argamassa exterior }(2,5 \mathrm{~cm})+\text { isolamento de poliestireno expandido }(3 \mathrm{~cm})+ \\
\text { painel de concreto leve moldado in loco }(8 \mathrm{~cm})\end{array}$ & 1,00 & 161 \\
\hline \multicolumn{3}{|l|}{ Cobertura } \\
\hline \multicolumn{3}{|l|}{$\alpha=0,9 / 0,6$ e 0,3} \\
\hline & $\begin{array}{c}\mathrm{U} \\
\left(\mathrm{W} / \mathrm{m}^{2} \cdot \mathrm{K}\right)\end{array}$ & $\begin{array}{c}\mathrm{Ct} \\
\left(\mathrm{kJ} / \mathrm{m}^{2} . \mathrm{K}\right)\end{array}$ \\
\hline telha de fibrocimento $(8 \mathrm{~mm})+$ laje de concreto $(8 \mathrm{~cm})$ & 3,79 & 189 \\
\hline $\begin{array}{l}\text { telha de fibrocimento }(8 \mathrm{~mm})+\text { isolamento de poliestireno expandido }(0,5 \\
\mathrm{cm})+ \text { laje de concreto }(8 \mathrm{~cm})\end{array}$ & 2,57 & 176 \\
\hline telha de fibrocimento $(8 \mathrm{~mm})+$ ático + laje cerâmica pré-moldada $(12 \mathrm{~cm})$ & 1,80 & 181 \\
\hline $\begin{array}{l}\text { telha de fibrocimento }(8 \mathrm{~mm})+\text { ático }+ \text { isolamento de poliestireno expandido } \\
(5 \mathrm{~cm})+\text { laje cerâmica pré-moldada }(12 \mathrm{~cm})\end{array}$ & 0,55 & 168 \\
\hline
\end{tabular}

Tabela 5 - Características das paredes exteriores com alta capacidade térmica

\begin{tabular}{|c|c|c|}
\hline \multicolumn{3}{|l|}{ Paredes exteriores com alta capacidade térmica } \\
\hline \multicolumn{3}{|l|}{$\alpha=0,9 / 0,6$ e 0,3} \\
\hline & $\begin{array}{c}\mathrm{U} \\
\left(\mathrm{W} / \mathrm{m}^{2} . \mathrm{K}\right)\end{array}$ & $\begin{array}{c}\mathrm{Ct} \\
\left(\mathrm{kJ} / \mathrm{m}^{2} . \mathrm{K}\right)\end{array}$ \\
\hline $\begin{array}{l}\text { painel de concreto moldado in loco, densidade de massa aparente igual a } \\
2.014 \mathrm{~kg} / \mathrm{m}^{3}(20 \mathrm{~cm})\end{array}$ & 3,19 & 403 \\
\hline $\begin{array}{l}\text { argamassa exterior }(2,5 \mathrm{~cm})+\text { isolamento de poliestireno expandido }(0,5 \mathrm{~cm}) \\
+ \text { painel de concreto leve moldado in loco }(20 \mathrm{~cm})\end{array}$ & 2,17 & 403 \\
\hline $\begin{array}{l}\text { argamassa exterior }(2,5 \mathrm{~cm})+\text { isolamento de poliestireno expandido }(3 \mathrm{~cm})+ \\
\text { painel de concreto leve moldado in loco }(20 \mathrm{~cm})\end{array}$ & 0,92 & 403 \\
\hline
\end{tabular}

Quadro 2 - Características construtivas das habitações mantidas fixas nas simulações

\begin{tabular}{|r|l|}
\hline Tipo de vidro & $\begin{array}{l}\text { vidro incolor } 4 \mathrm{~mm} \\
\text { fator solar: } 0,84\end{array}$ \\
\hline Área das janelas & $\begin{array}{l}\text { quartos: } 19,3 \% \text { da área da parede } \\
\text { sala: } 16,3 \% \text { da área da parede }\end{array}$ \\
\hline Paredes internas & $\begin{array}{l}\text { bloco de concreto furado de } 9 \mathrm{~cm} \text {, revestido por } \\
\text { argamassa }(2,5 \mathrm{~cm}) \text { nas duas faces }\end{array}$ \\
\hline Beiral & $\begin{array}{l}\text { beiral de } 50 \mathrm{~cm} \text { de largura, em } 3 \text { fachadas, } \\
\text { conforme o projeto original }\end{array}$ \\
\hline Venezianas & $\begin{array}{l}\text { nos quartos, metade da área das janelas } \\
\text { corresponde a venezianas de alumínio }\end{array}$ \\
\hline
\end{tabular}

\section{Forma de análise dos resultados}

Os resultados foram analisados através da comparação entre os níveis de desempenho obtidos de acordo com o procedimento simplificado e com o método de simulação, para as variadas combinações de $U$ e $\alpha$ da envolvente (paredes exteriores e cobertura). Procurou-se identificar se os limites estabelecidos no procedimento simplificado (Tabela 1) representam adequadamente as situações avaliadas através de simulação. Também se investigou a influência da capacidade térmica nesses limites e a possibilidade 
de outras formas de análise, como a simulação anual. Neste último caso, o desconforto foi estimado através dos graus-hora de calor e de frio anuais, tomando-se como referência o método adaptativo proposto pela ASHRAE 55 (AMERICAN..., 2010). De acordo com esse método, a temperatura de conforto é função da temperatura média mensal do ar exterior, sendo obtida através da Equação 1. A Tabela 6 apresenta as temperaturas médias mensais do ar exterior e as temperaturas de conforto para as três cidades analisadas.

$\mathrm{T}_{\mathrm{c}}=17,8+0,31 \times \mathrm{T}_{\text {Emed }}$

Eq. 1

Onde:

$\mathrm{T}_{\mathrm{c}}\left({ }^{\circ} \mathrm{C}\right)=$ temperatura operativa interna ideal, ou de "de conforto"; e

$\mathrm{T}_{\text {Emed }}\left({ }^{\circ} \mathrm{C}\right)=$ temperatura média mensal do ar exterior, sendo a equação válida para $\mathrm{T}_{\text {Emed }}$ entre 10,0 e $33,5^{\circ} \mathrm{C}$.

Para esta habitação, considerou-se a faixa de conforto correspondente a $80 \%$ de aceitação por parte de seus ocupantes, ou seja, seus limites superior e inferior encontram-se $3,5^{\circ} \mathrm{C}$ acima e abaixo da temperatura de conforto. Para cada hora do ano, caso a temperatura operativa dos ambientes se encontrasse acima ou abaixo desses limites, eram obtidos os graus-hora de calor e de frio respectivamente. A temperatura operativa é um dado de saída do EnergyPlus, sendo considerada como a média aritmética entre as temperaturas radiante média e do ar interior. Esse cálculo é aceitável, segundo a ASHRAE 55 (AMERICAN..., 2010), para ocupantes em atividade sedentária, não expostos à radiação direta e a velocidades maiores que $0,20 \mathrm{~m} / \mathrm{s}$, o que é o caso destas simulações. Os graus-hora de calor e de frio anuais foram obtidos para os dois quartos e a sala, e considerada a média aritmética entre esses valores, de modo a se obter um valor que fosse representativo da habitação como um todo.

\section{Resultados}

\section{Etapa 1: influência da transmitância térmica e da absortância da envolvente no nível de desempenho da habitação}

$\mathrm{Na}$ etapa 1 da pesquisa foram aplicados o procedimento simplificado e o método de simulação computacional da NBR 15575 (ABNT, 2013) para a habitação de interesse social com variados $U$ e $\alpha$ das paredes exteriores e da cobertura (ver item Método de pesquisa). O objetivo foi verificar se o procedimento simplificado representa de forma adequada a influência dessas duas propriedades térmicas no nível de desempenho da habitação. A capacidade térmica da envolvente foi praticamente a mesma em todas as situações e atendeu ao exigido pelo procedimento simplificado.

Tabela 6 - Temperatura média mensal do ar exterior e temperatura de conforto para Curitiba, São Paulo e Manaus

\begin{tabular}{|c|c|c|c|c|c|c|c|c|c|c|c|c|}
\hline \multirow[t]{2}{*}{ mês } & 1 & 2 & 3 & 4 & 5 & 6 & 7 & 8 & 9 & 10 & 11 & 12 \\
\hline & \multicolumn{12}{|c|}{ Curitiba } \\
\hline $\begin{array}{l}\mathrm{T}_{\text {Emed }} \\
\left({ }^{\circ} \mathrm{C}\right)\end{array}$ & 19,6 & 20,9 & 19,9 & 17,9 & 15 & 13,7 & 15,4 & 15,7 & 14,6 & 17,6 & 18 & 19,4 \\
\hline $\begin{array}{c}\mathrm{T}_{\mathrm{c}} \\
\left({ }^{\circ} \mathrm{C}\right) \\
\end{array}$ & 23,9 & 24,3 & 24,0 & 23,3 & 22,5 & 22,0 & 22,6 & 22,7 & 22,3 & 23,3 & 23,4 & 23,8 \\
\hline & \multicolumn{12}{|c|}{ São Paulo } \\
\hline $\begin{array}{l}\mathrm{T}_{\text {Emed }} \\
\left({ }^{\circ} \mathrm{C}\right)\end{array}$ & 21,2 & 22,4 & 21,7 & 20,8 & 17,5 & 16,8 & 17,3 & 18,3 & 17,7 & 20,5 & 20,2 & 20,9 \\
\hline $\begin{array}{c}\mathrm{T}_{\mathrm{c}} \\
\left({ }^{\circ} \mathrm{C}\right)\end{array}$ & 24,4 & 24,7 & 24,5 & 24,2 & 23,2 & 23,0 & 23,2 & 23,5 & 23,3 & 24,2 & 24,1 & 24,3 \\
\hline & \multicolumn{12}{|c|}{ Manaus } \\
\hline $\begin{array}{l}\mathrm{T}_{\text {Emed }} \\
\left({ }^{\circ} \mathrm{C}\right)\end{array}$ & 26,8 & 26,8 & 27,6 & 26,4 & 27 & 26,8 & 26,7 & 27,9 & 29 & 28,2 & 27,3 & 26,8 \\
\hline $\begin{array}{c}\mathrm{T}_{\mathrm{c}} \\
\left({ }^{\circ} \mathrm{C}\right)\end{array}$ & 26,1 & 26,1 & 26,4 & 26,0 & 26,2 & 26,1 & 26,1 & 26,4 & 26,8 & 26,5 & 26,3 & 26,1 \\
\hline
\end{tabular}

Nota: as temperaturas de conforto foram calculadas de acordo com a Eq.(1) e a partir dos arquivos climáticos disponibilizados por Roriz (2014). 
A aplicação do procedimento simplificado consistiu na verificação do atendimento aos limites para o $\mathrm{U}$ e o $\alpha$ das paredes exteriores e da cobertura (Tabela 1). Já no método de simulação computacional foram obtidas as temperaturas máximas e mínimas do ar no interior da habitação para os dias típicos de verão e inverno respectivamente, e seus valores comparados com as distintas faixas de desempenho (Tabela 2 para o verão, e Tabela 3 para o inverno). As simulações foram inicialmente conduzidas considerando-se 1 renovação de ar por hora. Caso o desempenho mínimo não tenha sido atendido, foram consideradas venezianas exteriores ocupando $50 \%$ da área das janelas da sala e 5 renovações de ar por hora em todos os ambientes.

\section{Desempenho térmico no verão}

Uma parte representativa dos resultados da aplicação do método de simulação da NBR 15575 (ABNT, 2013), referentes ao verão, é apresentada na Figura 2 (gráficos (a) a (f)). Cada ponto representa a temperatura máxima do ar na sala da habitação $^{2}$, no dia típico de verão, com uma distinta combinação de transmitância térmica e absortância da envolvente. Nas Figuras 2(a) a (c), referentes a Curitiba, São Paulo e Manaus, são alterados o $\mathrm{U}$ e o $\alpha$ da cobertura, enquanto as paredes externas permanecem sempre as mesmas $\left(\mathrm{U}_{\text {par exterior }}=2,11 \mathrm{~W} / \mathrm{m}^{2} . \mathrm{K}\right.$ e $\alpha$ par exterior $\left.=0,9\right)$. Já nas Figuras 2(d) a (f), o $\mathrm{U}$ e o $\alpha$ das paredes exteriores variam, enquanto a cobertura não é alterada $\left(\mathrm{U}_{\mathrm{cob}}=1,80 \mathrm{~W} / \mathrm{m}^{2} . \mathrm{K}\right.$ e $\left.\alpha_{\mathrm{cob}}=0,3\right)$. Como os níveis de desempenho pelo método de simulação são estabelecidos em função da diferença entre as temperaturas máxima interior e exterior, no gráfico são delimitadas as áreas correspondentes a cada um deles (desempenhos mínimo, intermediário, superior e insuficiente). Dessa forma, é possível observar no gráfico o nível de desempenho para cada caso simulado.

Com relação à influência do $\mathrm{U}$ e do $\alpha$ da cobertura no nível de desempenho de verão, pelo método de simulação (Figuras 2(a) a (c)), nota-se que a temperatura máxima interior varia consideravelmente em função da combinação de $U$ e $\alpha$, o que implica variados níveis de desempenho. Esses resultados indicam o impacto significativo que essas duas propriedades termofísicas da cobertura possuem no desempenho desse tipo de habitação, no verão, nesses três climas. O procedimento simplificado (Tabela 1) considera ambas as propriedades para a classificação do

${ }^{2}$ Conforme explicado no item Modelo de habitação e sua localização, o desempenho de verão se refere à temperatura do ar na sala, enquanto o desempenho de inverno se refere à temperatura do ar no quarto 2 . desempenho das coberturas, mas somente para as zonas bioclimáticas 3 a 8 . Para as zonas 1 e 2, considera apenas o $\mathrm{U}$, o que pode levar a análises equivocadas. Por exemplo, para o caso em destaque da Figura 2(a), que apresenta desempenho insuficiente, em Curitiba (zona 1), a cobertura com alta absortância $(\alpha=0,9)$ atende ao desempenho mínimo pelo procedimento simplificado, que exige $\mathrm{U} \leq 2,3 \quad \mathrm{~W} / \mathrm{m}^{2} . \mathrm{K}$, independentemente do valor de $\alpha$. O mesmo ocorre para suas paredes $\left(\mathrm{U} \leq 2,5 \mathrm{~W} / \mathrm{m}^{2} . \mathrm{K}\right)$, ou seja, essa habitação seria aprovada mesmo sem atender ao desempenho mínimo pelo método de simulação.

Para as paredes exteriores (Figuras 2(d) a (f)), distintas combinações de $\mathrm{U}$ e $\alpha$ também resultam em variados níveis de desempenho via simulação, embora essa variação seja menor do que a observada para as coberturas. Como os ganhos solares são maiores pela cobertura, variações nas propriedades termofísicas desse elemento construtivo implicam maiores variações na temperatura interior. A Norma contempla essa diferença, pois são especificados três níveis de desempenho para a cobertura, enquanto para as paredes é especificado apenas o desempenho mínimo. No entanto, da mesma forma que para as coberturas, o procedimento simplificado considera a influência somente do $U$ e do $\alpha$ das paredes para as zonas 3 a 8 . Isso não representa o que foi observado para Curitiba, podendo levar a erros, conforme já apresentado anteriormente.

Nas Figuras 2(a) a (f), todas as curvas são crescentes, indicando que, quanto maior a transmitância térmica tanto da cobertura quanto das paredes (Figura 2(d)), maior a temperatura máxima no dia típico de verão e, consequentemente, pior o desempenho da habitação. Isso ocorre porque, ao se aumentar o U, há maior transmissão de calor para o interior por essas superfícies. No entanto, a declividade das curvas reduz significativamente, conforme a absortância diminui. Por exemplo, em Manaus (Figura 2(f)), quando $\alpha_{\text {par exterior }}=0,9$, o nível de desempenho pode variar de "insuficiente" a "superior", dependendo do valor de $\mathrm{U}_{\text {par exterior. Já }}$ quando $\alpha_{\text {par exterior }}=0,3$, o nível de desempenho é sempre o mesmo (superior), e a variação de U apresenta pouca influência. Esse tipo de resultado também foi observado por Synnefaa, Santamouris e Akbarib (2007), ao avaliarem a influência de diferentes tipos de tintas conjugadas a telhados com variadas transmitâncias, no conforto térmico e no consumo energético de habitações em vários climas. Os autores notaram que coberturas com tintas com menor absortância não apresentavam tanta diferença no desconforto em função do valor de U. 
Figura 2 - Temperatura máxima do ar na sala da habitação para o dia típico de verão

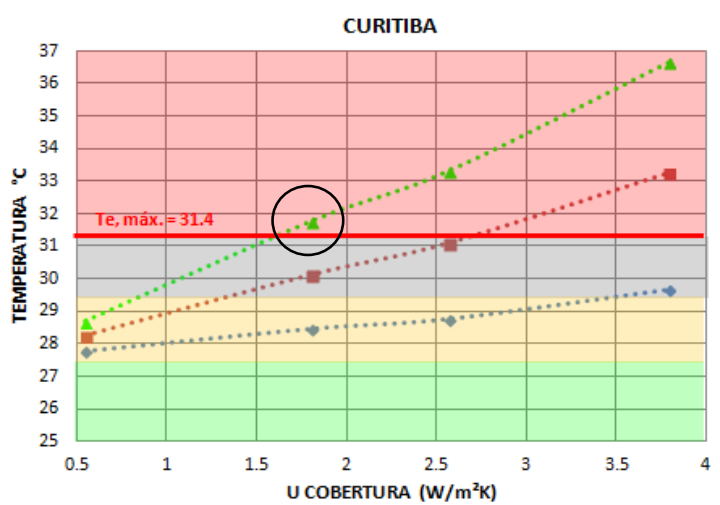

(a)

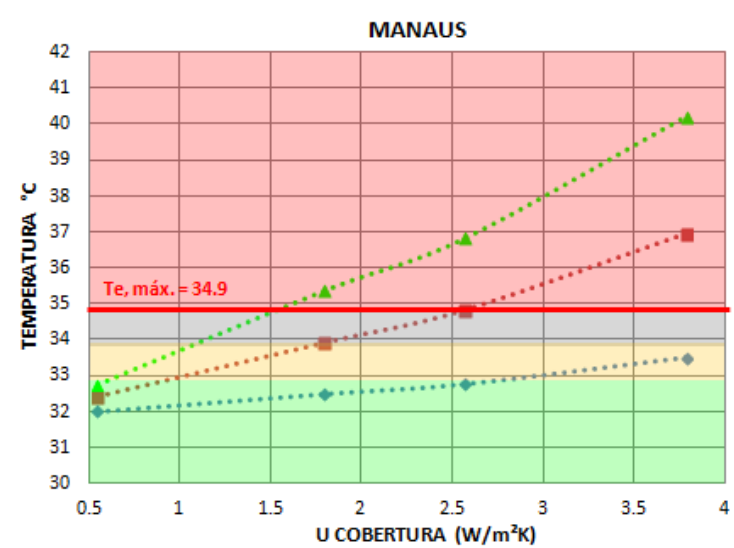

(c)

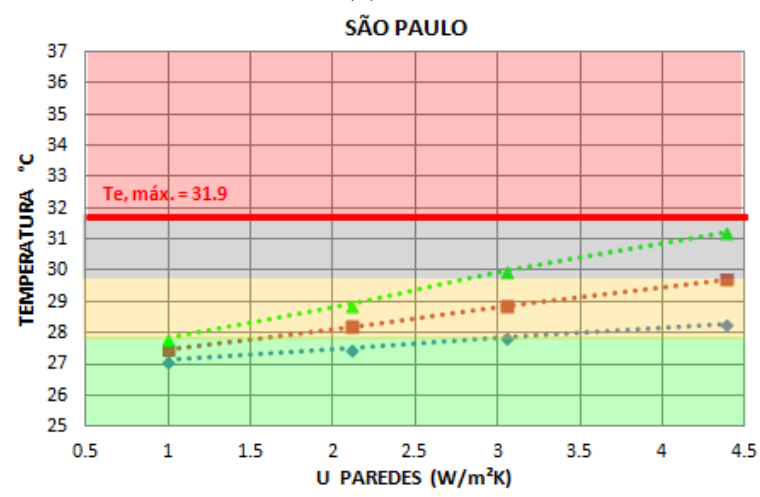

(e)

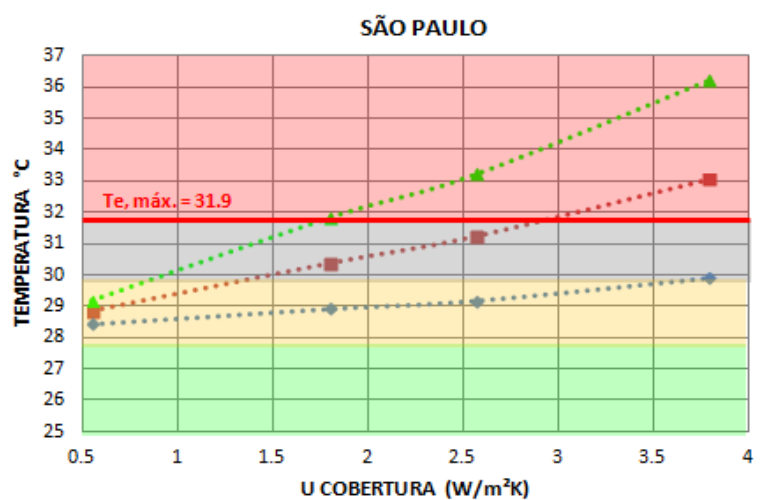

(b)

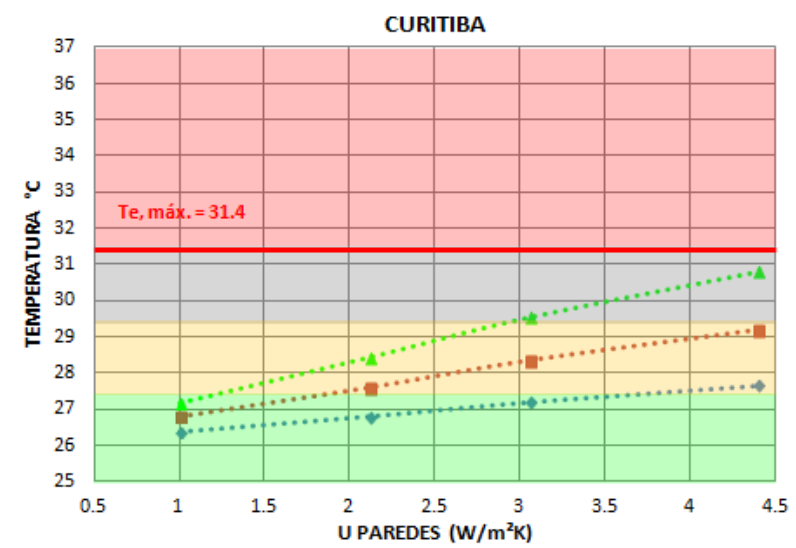

(d)

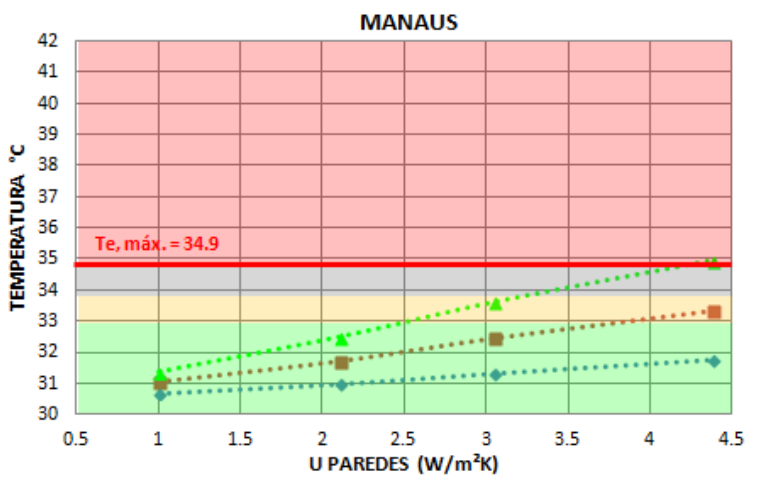

(f)

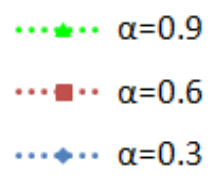

Nota: (a), (b) e (c): $U_{\text {par exterior }}=2,11 \mathrm{~W} / \mathrm{m}^{2} . K$ e $a_{\text {par exterior }}=0,9$; e (d), (e) e (f): $U_{\text {cobertura }}=1,8 \mathrm{~W} / \mathrm{m}^{2} . K$ e $a_{\text {cobertura }}=0,3$.

Esse impacto expressivo da absortância não é contemplado no procedimento simplificado (Tabela 1). Mesmo para absortâncias baixas, a transmitância das paredes e das coberturas ainda deve obedecer a valores máximos bem mais restritos do que os observados via simulação.
Nessas situações é que se observam as maiores incoerências entre o procedimento simplificado e o método de simulação. Há variadas situações nas quais uma envolvente com alta transmitância e baixa absortância não seria aprovada pelo procedimento simplificado, mas apresenta 
desempenho intermediário ou até superior pelo método de simulação. Por exemplo, em Manaus, para que uma cobertura com $\alpha=0,3$ tenha um desempenho superior de acordo com o procedimento simplificado, seu $U$ tem de ser menor ou igual a $1,0 \mathrm{~W} / \mathrm{m}^{2} . \mathrm{K}$ (Tabela 1$)$. No entanto, o caso com $\alpha=0,3$ e $U=2,57$ (Figura 2(c)) possui desempenho superior pela simulação. Uma cobertura com esse valor de U nunca seria aprovada nesse clima, pois a exigência para o desempenho mínimo é $\mathrm{U} \leq 2,3 \mathrm{~W} / \mathrm{m}^{2} . \mathrm{K}$.

Há uma tendência no setor da construção civil em se acreditar que edifícios com envolventes de menor transmitância são mais confortáveis termicamente. O impacto positivo do isolamento é de certa forma verdadeiro para o caso da habitação social estudado nesta pesquisa, mas, como demonstram os resultados, a absortância também possui influência expressiva no verão. Esse impacto conjugado da transmitância e da absortância, tal como foi observado na Figura 2, não é representado adequadamente nos limites do procedimento simplificado. Da forma como se encontra atualmente, a aplicação desse procedimento pode contribuir para gastos desnecessários e para a permanência de um equivocado entendimento sobre o assunto. Outra questão que deve ser discutida em futuras revisões é a razoável facilidade de alteração do valor da absortância das superfícies exteriores durante a vida útil do edifício, o que pode comprometer significativamente seu nível de desempenho.

Outro aspecto importante é que, no procedimento simplificado, o desempenho do edifício é avaliado considerando-se somente sua envoltória opaca. No caso do modelo de habitação de interesse social adotado neste artigo, esse elemento efetivamente possui grande impacto, mas a NBR 15575 (ABNT, 2013) trata de qualquer tipo de moradia, contemplando edificações com uma gama variável de características. Por exemplo, uma sala com $80 \%$ da área de sua fachada envidraçada seria avaliada somente por sua superfície opaca, o que poderia implicar a aprovação de uma moradia com desempenho insuficiente. A solução seria limitar o procedimento simplificado a habitações com características padrão, ou incluir nele outros parâmetros-chave que influenciam o desempenho, de modo que ele se torne mais completo.
Finalmente, a Norma permitia que se fizessem alterações na taxa de renovações de ar por hora no modelo simulado, caso este não tivesse sido aprovado inicialmente. Com essa alteração, a maior parte dos casos reprovados pelo método de simulação na etapa 1 passou a atender ao desempenho mínimo. No entanto, as mudanças no modelo simulado deveriam refletir reais alterações no projeto estudado.

\section{Desempenho térmico no inverno}

Resultados representativos para o dia típico de inverno podem ser vistos nas Figuras 3(a) a (d), para Curitiba e São Paulo. A cidade de Manaus está dispensada da simulação de inverno, segundo a Norma. Tem-se a temperatura mínima do ar no quarto $2^{3}$, para distintas combinações de transmitância e absortância da cobertura, mantendo-se as paredes exteriores fixas (Figuras 2(a) e (b)), ou vice-versa (Figuras 2(c) e (d)) Comparando-se os resultados da Figura 2 com o já observado para o verão, no item anterior, nota-se o seguinte:

(a) os níveis de desempenho obtidos para o inverno são melhores do que os para o verão, indicando maior facilidade para o atendimento às exigências de inverno estabelecidas pela Norma, para esse tipo de habitação, nesses climas;

(b) os valores de $U$ e $\alpha$ adotados tanto para as paredes exteriores quanto para a cobertura não acarretaram variações significativas nos níveis de desempenho da habitação como observado para o verão. Portanto, no inverno, é menor o impacto dessas propriedades no comportamento térmico desse tipo de edifício, em Curitiba e em São Paulo;

(c) todas as curvas são decrescentes, indicando que, quanto maior o $\mathrm{U}$ da envolvente, menor a temperatura interior e, consequentemente, pior o desempenho. Isso ocorre porque, quando o $\mathrm{U}$ aumenta, há maior perda de calor para o exterior pelas paredes e pela cobertura. A declividade dessas curvas é muito similar, independentemente do valor de $\alpha$, ou seja, contrariamente ao que se observou no verão, o impacto do valor de $\alpha$ não é tão significativo para a habitação nesses climas; e

(d) pode-se considerar que o atendimento às exigências para o verão, mais restritivas, seriam suficientes para garantir um adequado desempenho de inverno.

\footnotetext{
${ }^{3}$ Conforme explicado no item Modelo de habitação e sua localização, o desempenho de verão se refere à temperatura do ar na sala, enquanto o desempenho de inverno se refere à temperatura do ar no quarto 2 .
} 
Figura 3 - Temperatura mínima do ar no quarto 2 da habitação, para o dia típico de inverno

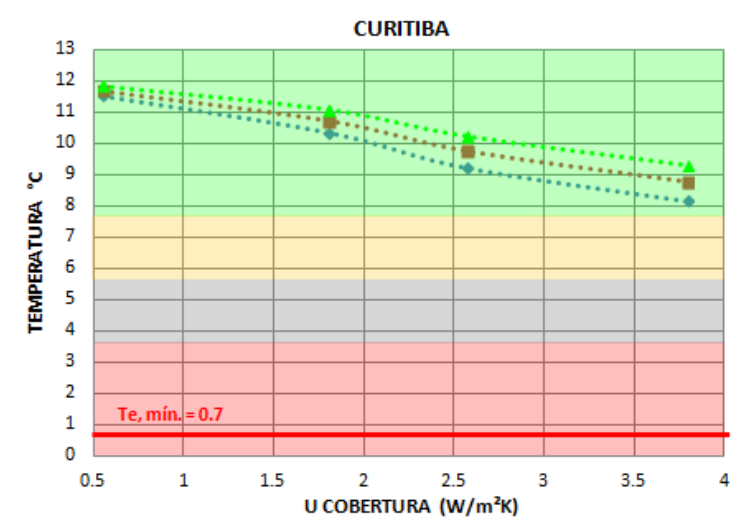

(a)

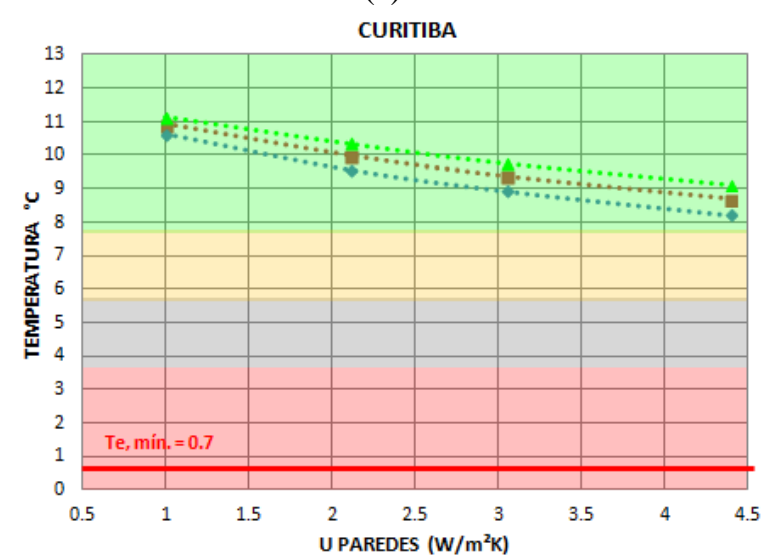

(c)

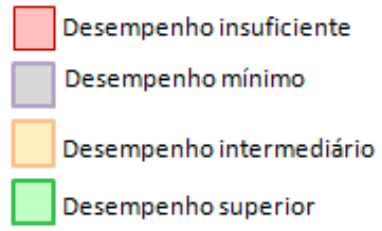

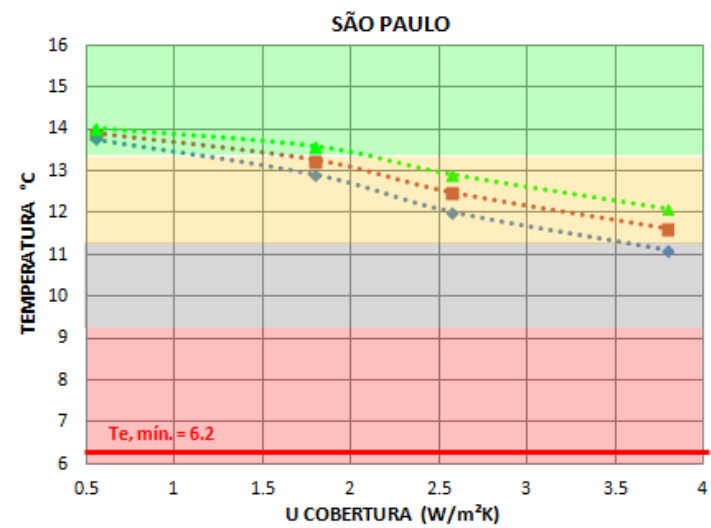

(b)

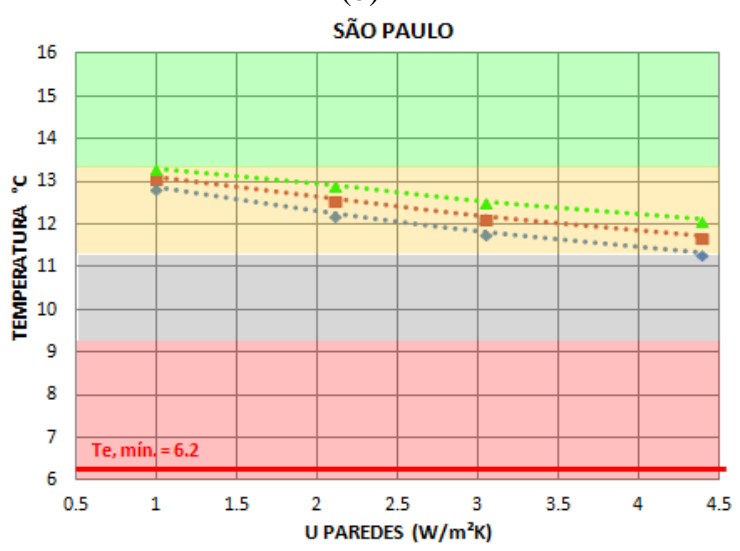

(d)

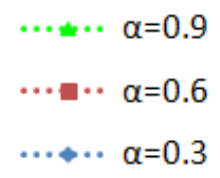

Nota: (a) e (b): $U_{\text {par exterior }}=2,11 \mathrm{~W} / \mathrm{m}^{2} . \mathrm{K}$ e a par exterior $=0,9$; e (c) e (d): $U_{\text {cobertura }}=1,8 \mathrm{~W} / \mathrm{m}^{2} \cdot \mathrm{K}$ e $\mathrm{a}_{\text {cobertura }}=0,3$.

\section{Etapa 2: influência da capacidade térmica das paredes exteriores no nível de desempenho da habitação, no verão e no inverno}

As simulações são idênticas às da etapa 1 , ou seja, para a habitação sem ganhos internos e com taxa de ventilação de 1 renovação de ar por hora, mas com as paredes externas de alta capacidade térmica. A Figura 4 apresenta parte dos resultados das simulações da etapa 2, selecionados como representativos para todos os climas e situações estudadas. Na Figura 4(b) cada ponto corresponde à habitação em Manaus, no dia típico de verão, com variados $U$ e $\alpha$ das paredes. A capacidade térmica das paredes é alta, igual a $403 \mathrm{~kJ} / \mathrm{m}^{2} . \mathrm{K}$, e a cobertura foi mantida sempre a mesma. A título de comparação, a Figura 4(b) corresponde às mesmas simulações da Figura 4(b), mas para a etapa 1 (menor capacidade térmica). De forma análoga, nas Figuras 4(c) e (d) têm-se os resultados para o dia típico de inverno, em São Paulo, para a habitação com paredes externas com baixa e alta capacidade térmica respectivamente. Os resultados indicam que o aumento da capacidade térmica não apresenta impacto significativo nos níveis de desempenho obtidos via simulação, tanto para o verão (Figuras 4(a) e (b)) quanto para o inverno (Figuras 4(c) e (d)), não se verificando, portanto, a necessidade de alterar as recomendações para esse parâmetro no método simplificado. 
Figura 4 - Habitação com variados $U$ e a das paredes, $U_{\text {cobertura }}=1,80 \mathrm{~W} / \mathrm{m}^{2} \mathrm{~K}$ e $a_{\text {cobertura }}=0,9$

$\mathrm{Ct}$ das paredes exteriores em torno de $180 \mathrm{~kJ} / \mathrm{m}^{2} . \mathrm{K} \mathrm{Ct}$ das paredes exteriores $=403 \mathrm{~kJ} / \mathrm{m}^{2} . \mathrm{K}$

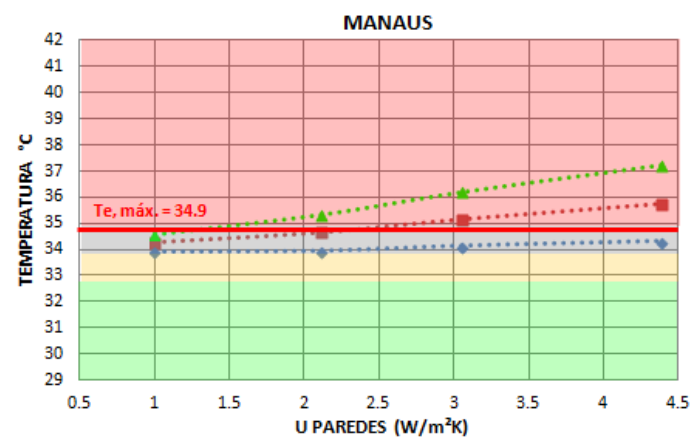

(a)

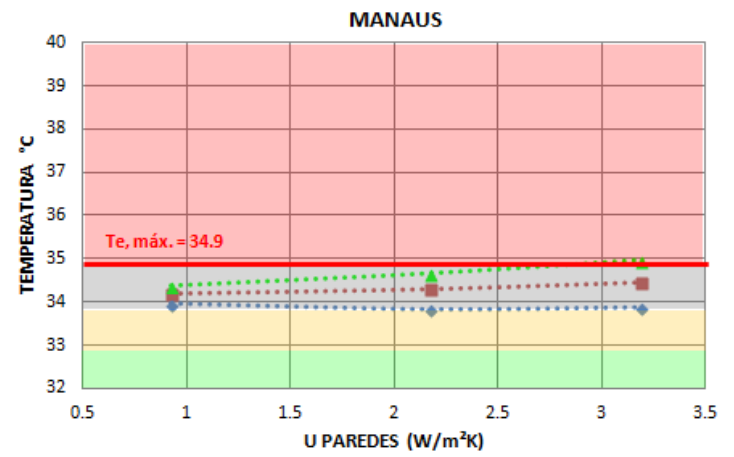

(b)

$\mathrm{Ct}$ das paredes exteriores em torno de $180 \mathrm{~kJ} / \mathrm{m}^{2} . \mathrm{K} \mathrm{Ct}$ das paredes exteriores $=403 \mathrm{~kJ} / \mathrm{m}^{2} . \mathrm{K}$

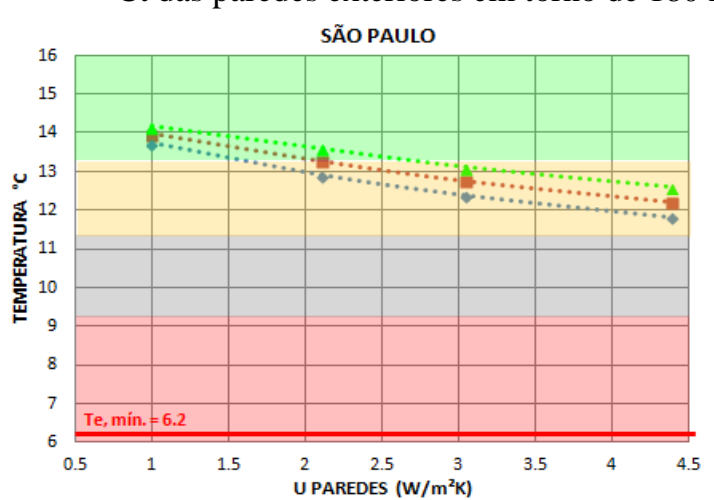

(c)

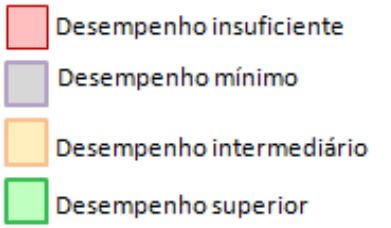

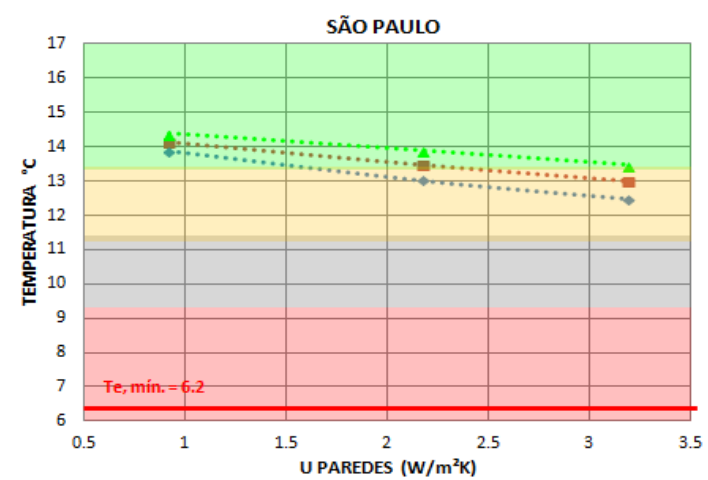

(d)

$$
\begin{array}{ll}
\cdots \cdots & \alpha=0.9 \\
\cdots & \alpha=0.6 \\
\cdots \cdots & \alpha=0.3
\end{array}
$$

Nota: (a) e (b) Dia típico de verão em Manaus e (c) e (d) Dia típico de inverno em São Paulo.

\section{Etapa 3: simulação horária anual}

Alguns autores criticam o fato de a NBR 15575 (ABNT, 2013) não considerar a simulação anual horária (SORGATO et al., 2012; SORGATO; MELO; LAMBERTS, 2013). De fato, esse tipo de simulação representa de forma mais apropriada o desempenho do edifício. Através dos graus-hora de desconforto por calor e por frio anuais, cujo cálculo foi indicado no item Método da Pesquisa, é possível contemplar a dimensão do desconforto em todo o ano. Além disso, atualmente se encontram disponíveis os arquivos climáticos anuais para 411 cidades brasileiras (RORIZ, 2014). Quanto aos dias típicos de verão e inverno, a Norma não indica um método para sua obtenção e os fornece apenas para 26 capitais brasileiras. Esses dados encontram-se no momento incompletos para entrada em programas de simulação. O usuário deve estimar alguns parâmetros, o que pode incorrer em erros consideráveis.

Foi feita a simulação horária para todos os casos já contemplados na etapa 1 da pesquisa, a fim de verificar se a influência da transmitância térmica e da absortância era a mesma observada para os dias típicos. Foram consideradas as condições reais de funcionamento da moradia, ou seja, com ganhos internos (segundo o RTQ-R (INNSTITUTO..., 2012), ver item Método da Pesquisa) e taxa de ventilação de 5 renovações de ar por hora em todos os ambientes. As Figuras 5(a) a (c) apresentam um exemplo para São Paulo, cujo U e $\alpha$ das paredes foi variado e a cobertura foi mantida sempre a mesma. A Figura 5(a) apresenta os graus-hora de desconforto por calor, a Figura 5(b), os por frio, e a Figura 5(c), o desconforto total anual (frio mais calor). 
Com relação ao desconforto por calor (Figura 5(a)), os resultados foram similares aos indicados no item Desempenho térmico no verão, para os dias típicos de verão, a saber:

(a) impacto significativo da transmitância e da absortância das paredes no desconforto;

(b) todas as curvas são crescentes, ou seja, em todas as situações, conforme maior o U das paredes exteriores, maiores os graus-hora de desconforto; e

(c) a declividade das curvas é muito maior para os casos com maior $\alpha$.

Todas as observações acima foram verificadas também para os outros climas e para os casos nos quais o $\mathrm{U}$ e o $\alpha$ da cobertura foram variados.

Já com relação ao desconforto por frio (Figura 5(b)), também se notaram resultados parecidos aos do item Desempenho térmico no inverno (dias típicos de inverno). Conforme maior o $U$ das paredes exteriores, maior é o desconforto, e as curvas possuem declividade similar (indicando o menor impacto de $\alpha$, se comparado com o verão). No entanto, as diversas combinações de $U$ e $\alpha$ resultam em uma considerável variação entre os valores de desconforto por frio. É possível visualizar que o desconforto por frio corresponde aproximadamente à mesma faixa de variação do desconforto por calor, o que não havia sido observado para os dias típicos de inverno. Esse resultado se dá devido à melhor representatividade do parâmetro graus-hora com relação à intensidade do desconforto na habitação, durante o ano todo.

Outra vantagem da simulação horária é a possibilidade de se obter o desconforto total anual (Figura 5 (c)). Dessa forma, as exigências para o calor e para o frio podem ser contabilizadas em um único parâmetro, fornecendo-se uma avaliação mais realista da habitação, ao se considerar o equilíbrio entre ambas as necessidades. Vê-se que os casos com valores de absortância $\alpha$ igual a 0,6 e 0,3 acabam por apresentar desempenhos muito próximos entre si. Não seria possível chegar a esse tipo de conclusão atualmente através do procedimento simplificado da Norma, ou do método de simulação, representando uma deficiência desses métodos. Distintos níveis de desempenho poderiam ser delimitados nesse gráfico, em função de distintos limites para os graus-hora de desconforto.

Figura 5 - Graus-hora de desconforto totais anuais para a habitação, com variados $U$ e a das paredes, $U_{\text {cobertura }}=1,8 \mathrm{~W} / \mathrm{m}^{2} \mathrm{~K}$ e $a_{\text {cobertura }}=0,9$, em São Paulo GRAUS-HORADE DESCONFORTO CALOR

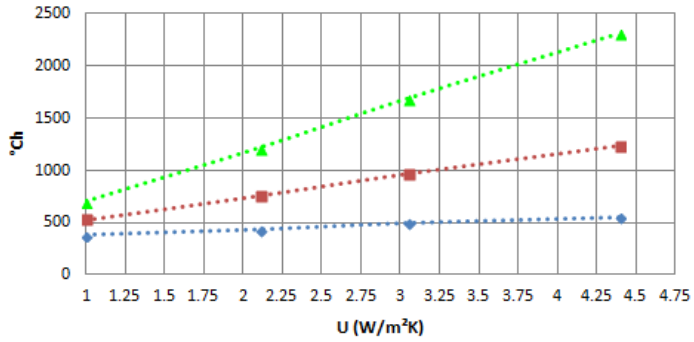

(a)

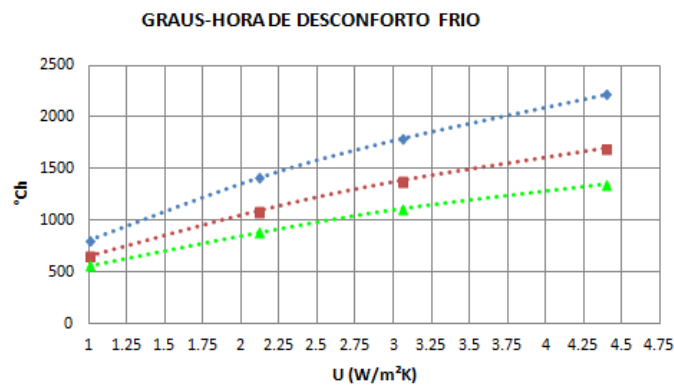

(b)

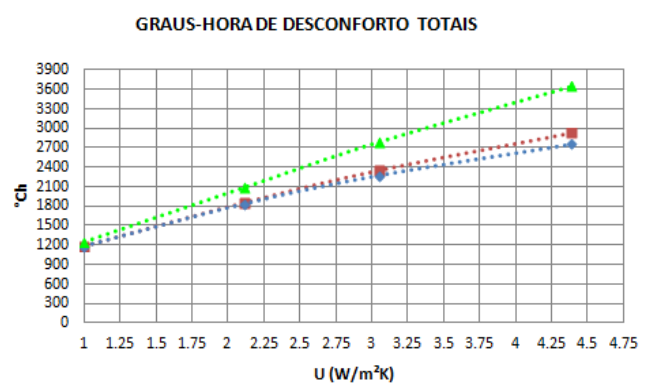

(c)

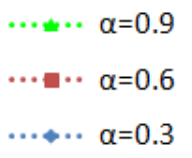

132 Chvatal, K. M. S. 


\section{Conclusão}

É indiscutível a importância da NBR 15575 (ABNT, 2013), que trata do desempenho de edificações habitacionais, no cenário da construção civil brasileira. Tendo surgido primeiramente em 2008, e com recente revisão em 2013, ela é uma das primeiras iniciativas, juntamente com a NBR 15220 (ABNT, 2005), de 2005, e o RTQ-R, que surgiu em 2010, que estabelece critérios para que se garanta o adequado desempenho térmico das habitações. Alguns autores têm levantado críticas com relação a essa norma, no entanto os trabalhos ainda são recentes e há a necessidade de estudos mais aprofundados que possam contribuir para seu aprimoramento. Em estudos anteriores, foram detectadas incoerências entre o procedimento simplificado proposto pela Norma e seu método de simulação. $\mathrm{Na}$ presente pesquisa procurou-se avaliar as razões dessas diferenças, através da aplicação de ambos os métodos em um modelo de habitação de interesse social, com variados valores de transmitância térmica e absortância das paredes exteriores e da cobertura.

Os resultados indicaram que o procedimento simplificado não representa de forma correta os impactos da transmitância e da absortância da envolvente avaliados pelo método de simulação, podendo levar a uma classificação de desempenho equivocada. Notou-se que na zona 1 , além do U, a absortância também influencia o nível de desempenho (sendo ela considerada atualmente somente nas zonas 3 a 8 ), e que paredes ou coberturas com baixas absortâncias permitem valores de transmitância muito maiores do que os limites prescritos pela Norma. A solução seria tornar o método mais representativo. Acredita-se na importância de métodos simplificados, pois possibilitam a rápida análise de habitações com baixo nível de complexidade, como é o caso das habitações de interesse social. No entanto, eles devem representar corretamente o comportamento térmico desses edifícios, considerando os parâmetros-chave que influenciam em seu desempenho, e informando claramente suas limitações.

Em continuidade, foi verificado se os resultados para as simulações anuais levariam às mesmas conclusões já observadas para os dias típicos. Em geral, são observados os mesmos padrões de gráficos, no entanto se verifica a melhor representatividade para o desconforto devido ao frio. Também a obtenção do desconforto total anual permite análises mais completas do edifício, com a identificação do impacto combinado das propriedades termofísicas da envolvente nas situações de frio e de calor.
Finalmente, considera-se essencial que discussões sobre a NBR 15575 (ABNT, 2013) levem em consideração sua coerência com a NBR 15220 (ABNT, 2005) e com o RTQ-R. Embora tenham objetivos e escopos distintos, é importante que esses documentos não sejam contraditórios, a fim de garantir sua confiabilidade e permitir sua implementação de forma apropriada.

\section{Referências}

\section{AMERICAN SOCIETY OF HEATING, REFRIGERATING AND AIR-CONDITIONING ENGINEERS. ANSI/ASHRAE Standard 55: \\ thermal environmental conditions for human occupancy. Atlanta, 2010.}

AMERICAN SOCIETY OF HEATING, REFRIGERATING AND AIR-CONDITIONING ENGINEERS. ASHRAE Standard 140: standard method of test for the evaluation of building energy analysis computer programs. Atlanta, 2011.

ASSOCIAÇÃO BRASILEIRA DE NORMAS TÉCNICAS. NBR 15220: desempenho térmico de edificações. Rio de Janeiro, 2005.

\section{ASSOCIAÇÃO BRASILEIRA DE NORMAS TÉCNICAS. NBR 15575: edificações} habitacionais: desempenho. Rio de Janeiro, 2013.

BRITO, A. C. et al. Contribuições Para o Aprimoramento da NBR 15575 Referente ao Método Simplificado de Avaliação de Desempenho Térmico de Edifícios. In: ENCONTRO NACIONAL DE TECNOLOGIA DO AMBIENTE CONSTRUÍDO, 14., Juiz de Fora, 2012. Anais... Juiz de Fora: ENTAC, 2012. DEPARTMENT OF ENERGY EFFICIENCY AND RENEWABLE ENERGY. EnergyPlus, Version 7.1.0.012. US: Department of Energy Efficiency and Renewable Energy, Office of Building Technologies, 2012. Disponível em: <http://apps1.eere.energy.gov/buildings/EnergyPlu s/>. Acesso em: 22 jun. 2012.

\section{DORNELLES, K. A. Absortância Solar de}

Superfícies Opacas: métodos de determinação e base de dados para tintas látex acrílica e PVA. Campinas, 2008. 160 f. Tese (Doutorado em Engenharia Civil) - Faculdade de Engenharia Civil, Arquitetura e Urbanismo, Universidade Estadual de Campinas, Campinas, 2008.

INSTITUTO NACIONAL DE METROLOGIA, NORMALIZAÇÃO E QUALIDADE

INDUSTRIAL. RTQ-R: regulamento técnico da qualidade para o nível de eficiência energética em edificações residenciais. Rio de Janeiro:

INMETRO, 2012. 
LIGGETT, R.; MILNE, M. Climate Consultant, version 5.5. UCLA Design Tool Group, USA, 2014. Disponível em: <http://www.energy-designtools.aud.ucla.edu/climate-consultant/requestclimate-consultant.php>. Acesso em: 15 dez. 2014.

LOURA, R. M.; ASSIS, E. S.; BASTOS, L. E. G. Análise Comparativa Entre Resultados de Desempenho Térmico de Envoltórias de Edifício Residencial Gerados Por Diferentes Normas Brasileiras. In: ENCONTRO NACIONAL DE CONFORTO DO AMBIENTE CONSTRUÍDO, 11., Búzios, 2011. Anais... Búzios: ANTAC, 2011.

MARQUES, T. H. T.; CHVATAL, K. M. S. A Review of the Brazilian NBR15575 Norm: applying the simulation and simplified methods for evaluating a social house thermal performance. In: SYMPOSIUM ON SIMULATION FOR ARCHITECTURE AND URBAN DESIGN, 4., San Diego, CA, 2013. Anais... San Diego, 2013.

\section{RORIZ, M. Arquivos Climáticos de Municípios}

Brasileiros. Disponível em:

$<$ http://www.labeee.ufsc.br/downloads/arquivosclimaticos/formato-epw>. Acesso em: $15 \mathrm{dez}$. 2014.

SORGATO, M. J. et al. Nota Técnica Referente à Avaliação Para a Norma de Desempenho NBR 15575 em Consulta Pública. Labee, Laboratório de Eficiência Energética em Edificações, UFSC, Florianópolis, 2012.
SORGATO, M. J.; MELO, A. P.; LAMBERTS, R. Análise do Método de Simulação de Desempenho Térmico da Norma NBR 15575. In: ENCONTRO NACIONAL DE CONFORTO NO AMBIENTE CONSTRUÍDO, 12., Brasília, 2013. Anais... Brasília: ANTAC, 2013.

SYNNEFA, A.; SANTAMOURIS, M.; AKBARI, $\mathrm{H}$. Estimating the Effect of Using Cool Coatings on Energy Loads and Thermal Comfort in Residential Buildings in Various Climatic Conditions. Energy and Buildings, v. 39, n. 11, p. 1167-1174, Nov. 2007.

\section{Agradecimentos}

Esta pesquisa foi financiada pela Financiadora de Estudos e Projetos (Finep), através da Rede de Pesquisa Desenvolvimento de métodos e metodologias para avaliação de desempenho de tecnologias inovadoras no âmbito do Sistema Nacional de Avaliação Técnica (Inovatec/Finep). O aluno Daniel Polistchuk elaborou o programa de pós-processamento dos dados, e as alunas Vanessa Damasceno, Tássia Marques e Natalia Calvi efetuaram a entrada de dados no EnergyPlus e elaboraram os gráficos.

Karin Maria Soares Chvatal

Instituto de Arquitetura e Urbanismo | Universidade de São Paulo | Av. Trabalhador Sãocarlense, 400 | São Carlos - SP - Brasil | CEP 13566-590 | E-mail: karin@sc.usp.br

\author{
Revista Ambiente Construído \\ Associação Nacional de Tecnologia do Ambiente Construído \\ Av. Osvaldo Aranha, $99-3^{\circ}$ andar, Centro \\ Porto Alegre - RS - Brasil \\ CEP 90035-190 \\ Telefone: +55 (51) 3308-4084 \\ Fax: +55 (51) 3308-4054 \\ www.seer.ufrgs.br/ambienteconstruido \\ E-mail: ambienteconstruido@ufrgs.br
}

